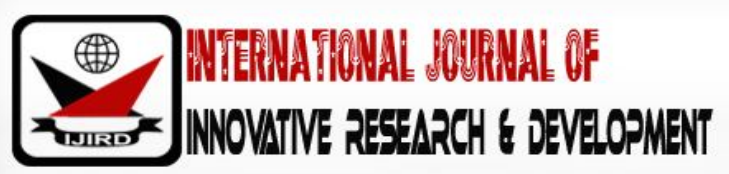

ISSN 2278 - 0211 (Online)

\section{Influence of Internet and Information Technology on Work and Human Resource Management}

\author{
Sunderlal Surendran \\ MBA (Training and Development, Fire and Safety), EMBA (Health and Safety Management), \\ Sydney, Australia
}

\begin{abstract}
:
Our earth without an iota of doubt has turned out to be a global community. The enhanced ways of communication, technological progress, computer plus internet have made for the horizons to get closer and altered the workings of the business world in a big way. Computers have modified the job of examining huge amounts of data, as they are priceless supporters in HR management starting from payroll processing to retention of records. ICT (Information and communication technology) is the combination of internet services and computers for the combined application of technology. ICT is frequently applied as a broadened synonym for IT (information technology), however is a more precise term that emphasizes the function of combined communications and the mixing of telecommunications, computers and required project software, middleware, storage, as well as audio-visual arrangements, which allow users to access, store, broadcast, and use information.
\end{abstract}

Keywords: Information technology, human resources management, organization structure, human resource management functions, human resources development, human resources information technology

\section{Introduction}

It is undoubtedly true when we say that the internet has converted our lives as also the way in which we converse, how we study, how we function and use free time, in spirit - it has comparatively altered every feature of human society that one can think of. The consequence of the Internet as well as information technology (IT) in both businesses in addition to the private field has developed significantly in the past years, with exponential expansion of Internet users and services extended. Unquestionably it also has its impact on the employees of organizations and their works in job plan, situations of work and in many other ways.

"Future prosperity is likely to hinge on the use of scientific and technical knowledge, the Management of information and the provision of services. The future will depend more on brains than brawn," (Barley, 1996: xvii).

"The HR professionals should remember that employees are the lifeblood of any company. If we create a great workplace experience for them, they'll pay you back one hundred fold in feedback and productivity", (Bryant, 2014).

Human Resources are most important and imperative for the achievement of any business. The roles, as well as skills of HR managers, have developed significantly in recent times because of the implementation and application of new technologies. The managers are nowadays able to execute the customary functions of procurement, preservation, development, and operation more efficiently and competently. The human resource managers are now able to assume more demanding functions in the organizations. The rising use of IT in human resource has considerably enhanced the competence of HR management activities as well as procedures, augmented their quickness and cut down cost. It has formed a useful and competent communication arrangement, employee commitment, talent management, employee growth, execution management, training as well as learning. additionally, the usage of HRIT [Human Resources Information Technology] furnishes value to the business and lift HR professionals' position in the establishment (Ulrich, 1997).

The conventional HRM style largely centered on supportive personnel actions for a business including gathering employee information, supervising individual performance, as well as enforcing organization policies. The new function of HR manager should comprehend the business policy and create the matching management policy on human resources to perk up delivered service and perform as a policy partner with the top management team (Beer, 1997). HR professionals should take on technologies that maintain organizational changes and develop an appropriate developmental environment to develop pioneering and knowledge-based organizations. 
According to Valverde et al. (2006), HR function is "all managerial action carried out at any level regarding the organization of work and the entry, development, and exit of people in the organization so that their competencies are used at their best in order to achieve corporate objectives. It includes the actors as well as their relevant responsibilities and tasks. HR managers are facing many challenges in present business scenario like Globalization workforce diversity, technological advances and changes in political and legal environment change in information technology. All these challenges increase the pressure on HR managers to attract, retain and nurture talented employee".

HR professionals cannot disregard these challenges instead they have to be in-line to plan and carry out groundbreaking mechanisms of devising skills and competencies of human resources to organize them to acknowledge the up-andcoming challenges.

\section{Methods}

These days, the world of business is experiencing a considerable change: the employee turn-over rate is turning out to be high, and both the organization arrangement as well as management design is also changing. The conventional HRM method fails to cope with such brisk changes: the conventional style primarily concentrates on helpful personnel activities for a business, for instance, gathering employee info, supervising individual performance, and enforcing organization policies. It is an inactive, docile carrying out, without self-provoked contribution into the planned issue to predict the disputes of tomorrow.

"Therefore, there comes a demand for the new HRM that should understand the business strategy, formulate the corresponding management strategy on human resources to improve delivered service, and act as a strategic partner with the top management team (Beer, 1997; Mohrman \& Lawer, 1997)."

To cope with the demand, there is a mounting stress on HRM to back up planned objectives and to concentrate on value-addition activities, which as a result contributes to the alteration in the job substance and the anticipations on Human Resource (HR) pros. Shrivastava et al. (2003) and Stone et al. (2006) observe that one among such changes is that of the extensive, modern use of Information Technology (IT) in assisting a range of HR activities. furthermore, the researchers anticipate that the raising application of Human Resource Information Technology (HRIT) can perk up the performance of HR professionals and involve in the company's internal consulting activities (Albers 1997). additionally, Ulrich (1997) states that the utilization of HRIT offers value to the organization and enhances the status of HR professionals in the organization. In a current theoretical development, Ulrich and Brockbank (2005) highlight the want for HR professionals to turn into business strategic partners.

These developments evoke a few queries concerning the interrelation between the HR function as well as the up-andcoming HRIT:

- Does the HRIT impact the altering HR function?

- How does HRIT back the altering role of HR function?

- How does HRIT control the HR function alteration?

\section{Results}

\subsection{IT in HR Function Transformation}

The past decades have attested the change of employee turning out to be the most valuable capital of a company and the rise of Human Resource Management (HRM) (Schuler, 1990). The reinforced management of human resources is at present the very spirit of a victorious business story. HR data has a variety of forms, including historical as well as current policies, job records, the personal data of employees, training programs, individual execution details and so on.

The HRIT allows for the option to store and frequently use the info as an electronic database, which is accessible by anyone, anytime and anywhere in the organization. For HR purpose, the HRIT can be enforced into HR chores and assist to improve the HR service delivery. The enforcement of IT into HR process can be achieved by means of the web-based tasks application. Publishing of the information, for example, is a most elementary and easiest execution of the HRIT (Gardner, Lepak \& Martol, 2003), which is the type of unidirectional communication from the upper management level to lower ones.

The information may be in the form of policies, news, as well as publications from the organization. Even though this uncomplicated function only needs to offer the info thru the website, it helps the organization by way of reduction in printing cost, the immediate delivery of the info online, and re- availability of information at any time.

The higher-level enforcement of HRIT is the computerization (Gardner, Lepak \& Martol, 2003): to utilize IT to administer the personal data. At this stage, the HRIT applies the intranets collectively to the internet. There are 2 types of data: one is the personal data of all workers, and the other the business data, like the arrangement of the organization, position array, wage range and so on. These fundamental data are utilized for all the HRIT applications of HR function. HRIT computerization can decrease the number of custom works, like maintaining business records, which formerly was done manually by the HR professionals. Now, the workers can modify their information by themselves, and HR professionals are freed from the time-intense tasks and concentrate on understanding the information (Gardner, Lepak \& Bartol, 2003).

The $3^{\text {rd }}$ level is the interface level, which goes ahead of easy info publishing and fundamental automation, and renders advanced profit and efficiency for HR function (Tansley, Newell \& Williams, 2001; Gardner, Lepak \& Bartol, 2003). Individuals besides obtaining information from the HRIT platform can also return their reviews. By electively separating out info, 
employees can acquire the initiative to self-sketch their career, which converts the task of planning from department-oriented to employee-oriented.

in addition, the interaction utility can connect the different sections jointly to share the service as well as use the public info to attain harmonious workflow. Via the interaction of workflow as well as the exchange of data, both internal, as well as external HR pros, can continue collaboration with continual HR program.

The top-level of HRIT application calls for envisioning of the HR function. From information to automation to interaction and then on to envision, HRIT begins to shift the HR function further than the conventional focus, out of the limits of HR section, and towards a planned one. Dependent on the plentiful data, HR pros can get the info via data statistics plus analysis, like program achievement appraisal, employee training, assessment record, and so on. Further, they can utilize the results of the statistical analysis to formulate plans to meet the future demand of human resource of a company and sketch salary-scale of employees.

Both the HRIT application as well as the HR function alteration have an effect on each other. The alteration of HR function needs controlling tools to help and assist managers in addition to employees to do better things and do things better. conversely, the enforcement of HRIT creates the shift of HR function realistic, and to some degree, altering the HR function drastically - demands HR pros to study the innovative and assorted skills for HRIT. This attracts HR professionals to pay notice to HRIT helpful and transformational activities. For this new HR function form, HRIT is the software platform that prompts HR function towards the system and information-based activities.

\subsection{HRIT in HR Function Transformation}

Even as the application of HRIT in human resource services has been developed ever since the 1990s, the consequences of IT on HRM are expanding over years (Florkowski, Olivas-Lujan, 2006). in view of its capability to contribute to the overall functioning of the organization, HRIT maintains the basic shifts regarding the HR function.

Hempel (2004) has formulated a model of the dealings between technology and HRM, including the plan of the business plus work, HR professionals, and workers. Based on the model it has been stated that a new technology can source the alterations in organizing the business and work plan, and these changes will transform the effect of HR practices. HR pros can make use of powerful technologies to promote changes within the organization, by managing the inventive and wellinformed employees. From this viewpoint, the connection between HRIT and HR function is a type of interaction. Hempel (2004) regards that the HR pros are in the catch-up place. Because technology changes take place first the arrangement of the work, for instance, virtual overall workgroups, the functions of HR has to develop so as to sustain these changes. HR professionals are already into the revamp process, therefore they must deeply understand the business on both functional as well as planned sides to deal with and sustain the innovation.

\subsection{HRIT Functions}

When taking into consideration the effect of HRIT on the HR day by day activities, some investigators have analyzed HRIT from its functions, for instance the e-recruiting scheme, e-selection scheme e-performance scheme, and e-compensation scheme, and remarked that HRIT can have both optimistic as well as pessimistic pressures on HR occupation (Stone, Romero \& Lukaszewski, 2006). by the study on these functions, the comprehension of HRIT power on the alteration of HR function can begin from the info flows, social communication patterns, apparent control of individuals as well as system approval (Ashbaugh \& Miranda, 2002; Stone, Romero \& Lukaszewski, 2006).

\subsection{Information Flows}

The application program of HRIT can alter the flow of the information considerably, as the system allows users to collect more capable, distribute and access information (Stone, Romero \& Lukaszewski, 2006). For instance, while recruiting new employees there is no need of any kind of face-to-face interview or inquiry as HRIT can help the applicants to collect information about jobs easily and provide direct access with the HR pros. Simultaneously HRIT can also give regular feedback to employees, and perk up the sustaining ability of a business. Apart from this, the information that flows across different departments can assist the HR professionals to apply the complete and expert information for policymaking.

Consequently, HRIT lets the HR professionals handle a huge amount of information with great precision. The mechanization of HRIT is the most excellent way to advance the efficiency, and hence it is an important contributor to HR functioning. however, in a few cases, the arrangement may not be as helpful as conventional methods (Haines \& Lafleur, 2008).

\subsection{Social Interactions}

The HRIT decreases personal interactions in organizations. Each and every employee can connect through internet by means of internal email and telecommuting system and this helps in carrying out the work without any location constraint. From this standpoint, HRIT extends interaction among the personnel within the organization. nevertheless, alternatively, as the face-to-face interactions decrease, HRIT may have pessimistic consequences on faith levels among managers plus employees (Stone, Romero \& Lukaszewski, 2006), and this requires the HR professionals to reconstruct the faith and association among employees. 


\subsection{Apparent Control}

The usual workforce management is to direct and administer the employees. With the use of HRIT, regardless of whether the controlling of people is more viable than earlier or not is dubious. On one side, the expanding worker and manager self-service request more freedom in managing employees. In this sense, such decentralization gives more flexibility on the administration of employees (Ashbaugh and Miranda, 2002). The supervisors stated increase in the level of satisfaction due to HRIT frameworks in light of the fact that the frameworks give more noteworthy measures of criticism and control over their employee's performance than customary ways (Stone, Romero and Lukaszewski, 2006). According to Stone, Romero \& Lukaszewski, (2006) "On the other hand, the same HRIT system also has more tightly control on individual performance, due to reducing the freedom and controls levels of individuals. For example, the managers can exactly check the time of each employee spend on their tasks. It may lead to negative reactions to the e-performance management systems. Moreover, invalid data about the performance of employees, and employees may behave in rigid ways that make them look good from the systems also damage the organization in the long run (Stone, Romero \& Lukaszewski, 2006)".

To summarize, HRIT drives the customary HR function to convert and alters the task of management. HRIT conveys the capability for all members to make simpler their work, gauge activities, give an immediate opinion and decrease waste of time (Ashbaugh \& Miranda, 2002). The enforcement of HRIT conforms to the wants of end-users and the organization. or else, the reduced social interactions and unconstructive effect on both quality control as well as information correctness can harm the advantage of organization (Stone, Romero \& Lukaszewski, 2006). HR professionals must deal carefully and pay attention to the drawbacks while they reap the benefits conveyed through HRIT to the organization.

\section{Conclusion}

The rising awareness of info and freedom of employees have demanded clear and understandable human resource information. They pay notice to modified human resource expansion project, comprehend self-management, as well as master career expansion on own initiative, and they are as well keen to pick appropriate studying program. HRIT renders opportunity to every person in the business to contribute in HRM works, plus de-concentrates some duties of HR function to them. The employees can pick the HR info as well as service on their own. Consequently, they can obtain the information at any instant and attain the activity to get the end result. To some degree, the employees no more have to wait for others to solve their issues or to find answers to their queries since those can be effortlessly meted out through HRIT, like communication online or receiving a reply from knowledge database.

By means of the interactive as well as dynamic HRIT, HR section can continue the working system, training plus motivation consistent with different individual demands, and allow the employees to apply self-control plus, control their own future. additionally, dependant on HRIT, employees can get and preserve their individual info like attendance, payment, training proof and so on. furthermore, the communication between employees as well as managers is as well different as the conventional one. The feedback of worker can be straightaway transmitted to the concerned manager or department through the HRIT platform, which makes certain that any issue can be dealt with precisely and efficiently. Thus, the HRIT facilitates the employees to apprehend self-control and self-service, gives more chances to engage low-level workers into management problems, and promotes the whole organization to acknowledge this new type of management style.

Consequently, the HRIT conveys independency to employees while they confront HR issues. Likewise in the recruitment process, the candidate can manage their applications via the internet, revise personnel info punctually to have relative benefit; when they are acknowledged by the company. Similarly, they will be able to plan their own career, as well as plan for different training program rendered by the employer which may be useful for their future. to sum up, employees can decide the manner in which they want to develop and apprehend value creation for the entire organization.

To conclude HRIT has a major role to play in planned HR tasks. It alters the management way of conventional HRM, facilitates that management activities can be performed at any level without additional obstruction. likewise handling the information exchange, the planned HR activities like workplace learning, career managing, business process re-engineering, etc. can be developed in an enhanced manner and supported with HRIT application, which helps the HR to function on a more important situation.

\section{References}

i. Barley, S. (1996). The New World of Work. Pamphlet, British-North American Committee, London.

ii. Bryant, Craig, "Five Predictions for Where HR Technology Is Going in 2014", www.tlnt.com.

iii. $\quad$ Urich, D. (1997). Human Resource Champions: The Next Agenda for Adding Value and delivery Results. Harvard Business School Press, Boston.

iv. Beer, M. (1997), "The transformation of the human resource function: Resolving the tension between a traditional administrative and a new strategic role", Human Resource Management, 36(1).

v. Valverde, M., Ryan, G., \& Soler, C. (2006). Distributing HRM responsibilities: a classification of organizations, Personnel Review, 35, (6), 618 - 636.

vi. Schuler, R. S. (1990). Repositioning the Human Resource Function: Transformation or Demise? Academy of Management Executive, 4(3), 49-60. 
vii. Mohrman, S. A. \& Lawler, E. E. (1997). Transforming the human resource function. Human Resource Management, 36(1), 157-162.

viii. Shrivastava, S. \& Shaw, J. B. (2004). Liberating HR through technology. Human Resource Management, 42(3), 201-222.

ix. Stone, D. L., Stone-Romero, E. F., \& Lukaszewski, K. (2006). Factors affecting the acceptance and effectiveness of electronic human resource systems. Human Resource Management Review, 16(2), 229-244.

x. $\quad$ Albers, M. (1997). Information engineering: Creating an integrated interface: In M. Smith, G Salvendy \& R. Koubek (Eds.), Proceedings of the 7th International Conference on Human Computer Interaction, pp. 213-216. New York: Elsevier

xi. $\quad$ Ulrich, D. and W. Brockbank (2005), Role Call, People Management, Vol. 11 No. 12, pp 24-28.

xii. Gardner, S. D., Lepak, D. P., \& Bartol, K. M. (2003). Virtual HR: The impact of information technology on the human resource professional. Journal of Vocational Behavior, 63(2), 159-179.

xiii. Tansley, C., Newell, S., \& Williams, H. (2001). Effecting HRM-style practices through an integrated human resource information system - An e-greenfield site? Personnel Review, 30(3), 351-370.

xiv. Florkowski, G. W. \& Olivas-Lujan, M. R. (2006). The diffusion of human-resource information-technology innovations in US and non-US firms. Personnel Review, 35(6), 684-710.

xv. Hempel, P. S. (2004). Preparing the HR profession for technology and information work. Human Resource Management, 43(2-3), 163-177.

xvi. Stone, D. L., Stone-Romero, E. F., \& Lukaszewski, K. (2006). Factors affecting the acceptance and effectiveness of electronic human resource systems. Human Resource Management Review, 16(2), 229-244.

xvii. $\quad$ Ashbaugh, S. \& Miranda, R. (2002). Technology for human sources management: Seven questions and answers. Public Personnel Management, 31(1), 7-20.

xviii. Haines, V. Y. \& Lafleur, G. (2008). Information technology usage and human resource roles and effectiveness. Human Resource Management, 47(3), 525-540. 